\title{
Response to a Review of My Book
}

\section{The Mathematical Intelligencer encourages comments}

about the material in this issue. Letters to the editor

should be sent to either of the editors-in-chief, Chandler

Davis or Marjorie Senechal.

T his is my response to the review by Osmo Pekonen of The Artist and the Mathematician, in Vol. 31 (2009), No. 3. I found the review of my book The Artist and the Mathematician, which details the story of the fictitious mathematician Nicolas Bourbaki somewhat unfair. Mr. Pekonen disagrees with my characterization of Bourbaki as having played a significant role in the structuralist movement in mid-twentieth century France. Suffice it to say (as indeed I do in the book) that some of the members of the structural movement were also mathematicians-prominent among them Raymond Queneau-and that most mathematicians would agree that the approach to mathematics taken by Bourbaki was essentially "structuralist" in its very nature.

Pekonen writes, "Aczel tends to overemphasize the impact of Bourbaki both inside and outside the mathematical community." Perhaps Mr. Pekonen is much younger than myself. Most mathematicians of my age and older, and especially those with an international outlook, know quite well how influential Bourbaki really was-during the time of "his" greatest productivity. As I point out in the book, the whole "New Math" movement in the United States was a direct outcome of Bourbaki's work and immense influence on mathematics.
But the unkindest cut of all is when Pekonen writes: "He [Aczel] most often fails when he needs to explain a mathematical concept. The book is infested with errors and misconceptions." Now, I've been called many things in my long career as a writer of books on mathematics, but nobody has, until now, accused me of failing to explain mathematical concepts. In a fair review_-by a book-review editor, no less! I would have expected that an outrageous statement such as this one be followed by at least one example of how I "failed" to explain a mathematical concept. None was given. Nor did Mr. Pekonen give a single example of the "errors and misconceptions" that he supposedly found in my book. If he found any, I would appreciate being informed of exactly what these "errors and misconceptions" were. Such unsubstantiated accusations have no place in a review in a professional journal.

Finally, let me point out a ludicrous (and self-serving) element of Pekonen's review. Part of my book was devoted to the misadventures of a key member of the Bourbaki group, the mathematician André Weil, in wartime Finland. This part was based largely on Weil's own recollections in his autobiography, The Apprenticeship of a Mathematician (Boston: Birkhäuser, 2002), and my book makes ample references to Weil's published book. During the Second World War, Weil was arrested as a spy by the Finnish police, and he felt that there was a good chance that he would be executed by Finnish officials. Mr. Pekonen, whose address is in Finland, seems to have taken offense to my quotations from Weil's autobiography. Furthermore, he found it appropriate to quote an article he himself has written, in which he purportedly "proves" (how does one prove such a thing?) that Weil, in fact, was not in danger of execution. I fail to see the importance of Pekonen's argument. Does it matter at all whether Weil was or was not about to be executed? What matters to me is how Weil felt while a wartime prisoner in Finland. Whether or not an execution would have actually taken place if he had remained in custody is a completely moot question.

\author{
Amir D. Aczel \\ Center for the Philosophy and History of Science \\ Boston University \\ Boston, Massachusetts \\ USA \\ e-mail: aczel@bu.edu
}

